\title{
Lateral Clipping of Canopy Influences the Microclimate and Development of Apothecia of Sclerotinia sclerotiorum in Carrots
}

\author{
Cezarina Kora and Mary Ruth McDonald, Department of Plant Agriculture, and Greg J. Boland, Department of \\ Environmental Biology, University of Guelph, Guelph, Ontario, Canada N1G 2W1
}

\begin{abstract}
Kora, C., McDonald, M. R., and Boland, G. J. 2005. Lateral clipping of canopy influences the microclimate and development of apothecia of Sclerotinia sclerotiorum in carrots. Plant Dis. 89:549-557.

Four canopy management treatments were evaluated in carrot (Daucus carota) production in Bradford Marsh, Ontario, in 2001 and 2002: (i) unclipped control; (ii) unclipped canopy with manual removal of collapsed senescing leaves at 2-week intervals following the first appearance on the soil; (iii) lateral clipping of the canopy at the initial emergence of apothecia, leaving the debris in the furrow, and (iv) lateral clipping of the canopy with manual removal of the debris from the furrow. Clipping reduced the canopy width by ca. $20 \%$ on both sides of the carrot bed by cutting off overlapping leaves above the furrow and senescing foliage on the soil surface. Maximum air and soil temperatures were up to 9.2 and $3.1^{\circ} \mathrm{C}$ lower, respectively, and relative humidity was up to $30 \%$ higher in unclipped canopies than in clipped canopies. The total number of apothecia in clipped plots was reduced by 74 and $76 \%$ compared with unclipped plots in 2001 and 2002, respectively. Canopy clipping reduced the quantity of apothecia in the crop by creating an unfavorable microclimate for the development of $S$. sclerotiorum without affecting the fresh foliar and root weights of carrot at harvest. The presence of clipped foliar debris in the furrow affected the number of apothecia in 2001; however, apothecia under the debris are unlikely to contribute to the overall inoculum in the crop. Lateral clipping also appeared to control Sclerotinia rot of carrot where it occurred (in 2001). This is the first report that documents and quantifies the effects of canopy architecture on the microclimate, development of apothecia of S. sclerotiorum, and Sclerotinia rot in carrot crops.
\end{abstract}

Additional keywords: epidemiology, microclimate modification, storage rot

Sclerotinia rot, caused by Sclerotinia sclerotiorum (Lib.) de Bary, is an important disease of carrots (Daucus carota L.) in many carrot production areas of the world $(28,31,43)$. The disease affects carrots in the field and storage; however, crop losses are particularly prevalent during long-term storage. In Canada, crop losses up to 30 and $50 \%$ have been reported in storage $(2,19)$. Currently available management practices often do not provide effective control of this disease. In addition, commonly cultivated carrot cultivars do not include genotypes resistant to $S$. sclerotiorum (46). The challenge of managing this disease in Canada increased with the withdrawal from the market of Benlate (benomyl), which was the only fungicide available for the control of Sclerotinia rot of carrot (SRC). Cultural methods such as harvesting during dry weather (34), grading out cull roots (32), rapid cooling of harvested roots (38), and main-

Corresponding author: G. J. Boland

E-mail: gboland@uoguelph.ca

Accepted for publication 8 January 2005.

DOI: 10.1094/PD-89-0549

(C) 2005 The American Phytopathological Society taining air temperatures of 0 to $1^{\circ} \mathrm{C}$ and relative humidity of 95 to $100 \%$ $(23,29,40,46)$ can suppress development of SRC in storage, but may be ineffective if disease is not adequately managed in the field.

Sclerotinia rot of carrot is characterized by two distinct and related epidemics during the course of one crop: the preharvest epidemic occurring in the field, and the postharvest epidemic occurring in storage (28). Preharvest epidemics of SRC may be initiated by airborne ascospores originating from apothecia $(14,22)$ or mycelium originating from germinating sclerotia of $S$. sclerotiorum in soil (19). Recent epidemiological studies suggested that ascospores originating from within-field apothecia are probably responsible for initiating important epidemics of SRC in Ontario because their release likely coincides with the susceptible stage of the crop (27). Disease of carrot roots in storage is a direct consequence of foliar infection in the field and occurs via the crown $(19,22,31)$. Mycelium arising from these infected roots can rapidly spread to adjacent roots forming enlarging pockets of infection and causing extensive decay.

Carrots possess architectural and phenological attributes with epidemiological significance that can contribute to the development of S. sclerotiorum and SRC. Typically, carrots develop a large, dense canopy over the soil. A closed crop canopy may create conditions that are conducive to the development of the fungus by maintaining extended periods of high moisture, obstructing direct light penetration and aeration, and buffering fluctuating microclimate variables $(1,25)$. In addition, carrots become susceptible to infection by $S$. sclerotiorum when senescing foliage is present within the canopy (22). Sclerotinia rot mainly affects older leaves in the lower part of the carrot canopy and is encouraged by the development of dense and lodged foliage. Disease first appears as localized lesions on senescing leaves in contact with soil. Mycelium arising from these lesions can readily colonize adjacent senescing leaves, foliar debris on the soil surface, or healthy leaves of neighboring plants, and advance toward the crown from where it enters the root. Therefore, plant-to-soil and plant-to-plant contacts are important for the initiation of epidemics and secondary spread of the pathogen.

The effect of plant architecture on microclimate within the canopy, development of S. sclerotiorum, and Sclerotinia diseases has been demonstrated for a number of crops. Denser, taller, and lodged canopies have been associated with cooler and moister microclimates, greater numbers of apothecia, and higher disease incidence or severity in beans (Phaseolus vulgaris L.) $(4,12,16,20,42,52)$, soybean (Glycine max L.) (6), canola (Brassica campestris L., Brassica rapa L.) $(50,51)$, peanut (Arachis hypogaea L.) (11,13), and potato (Solanum tuberosum L.) (36). These studies suggested that disease avoidance may be a significant strategy for improving the management of diseases caused by Sclerotinia spp. Genotypes with upright and compact growth habits may offer an important source in selection for architecturally based disease avoidance mechanisms.

Various methods devised to manipulate the canopy architecture and maximize disease avoidance have been effective in managing diseases caused by Sclerotinia spp. in several crops. Cultural methods such as using wider row spacing, lower planting density, cultivars with a porous canopy, or minimizing lodging by lifting the canopy have consistently reduced the severity of white mold of bean $(4,15,21,24,52)$. Breeding cultivars for an upright growth habit, lodging-resistance, 
and partial physiological resistance has also improved the management of white mold of bean and Sclerotinia stem rot of soybean $(5,6,35,39)$. Horizontal pruning of the top part of the canopy resulted in reduced incidence of Sclerotinia blight (Sclerotinia minor Jagger) of peanut (11) and lower severity of Sclerotinia crown and stem rot (Sclerotinia trifoliorum Eriks.) of crimson clover (Trifolium incarnatum L.) (37).

Management of carrot canopy by lateral clipping is recommended (46) and practiced commercially in Washington State (28) for the cultural control of SRC. However, the control mechanisms and effects of this practice on microclimate, development of the pathogen, disease, or carrot crop have not been reported. The objectives of this study were to evaluate the effects of laterally clipping a portion of the carrot canopy, removing the clippings, and manually removing the senescing leaves on canopy architecture, microclimate within the crop, development of apothecia of S. sclerotiorum, management of SRC, and carrot yield. It was hypothesized that enhanced air circulation and light penetration within an opened canopy would suppress the development of apothecia, and removal of senescing tissue from carrot plants would contribute to reduction of potential infection sites.

\section{MATERIALS AND METHODS}

Experimental site. Trials were conducted on organic (muck) soil $(60 \%$ organic matter, $\mathrm{pH} 5.5$ to 6.5 ) naturally infested with $S$. sclerotiorum at the Muck Crops Research Station, Bradford Marsh, Ontario, in 2001 and 2002. Both experiments were conducted in the same area of the field where 2- to 3-year rotations of carrot cropping during the previous 50

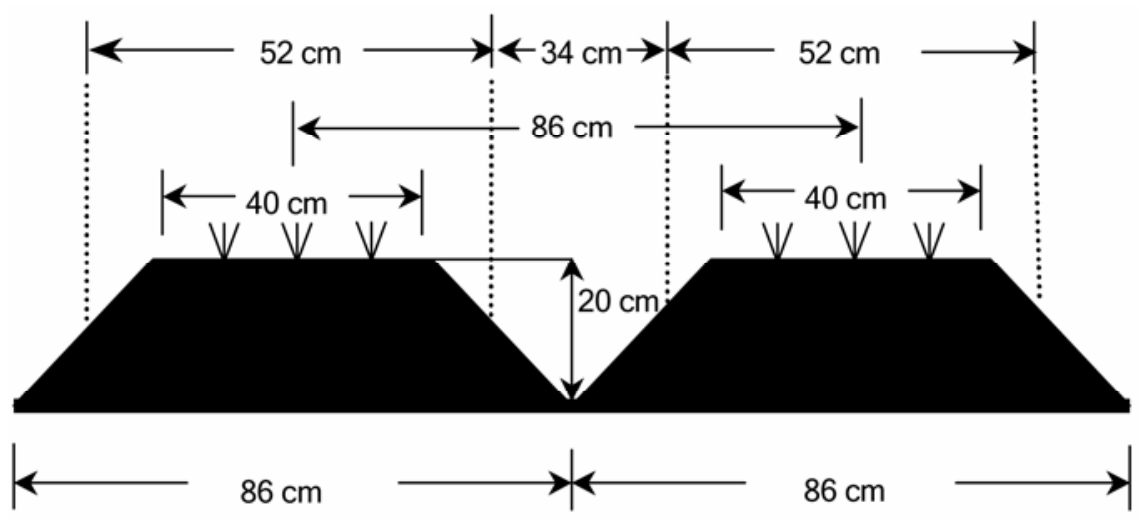

Fig. 1. Diagram of typical carrot beds in the cultivation system at the Muck Crops Research Station, Bradford Marsh, Ontario. Dotted lines indicate tracks of the hedge trimmer during lateral clipping of the carrot canopy.
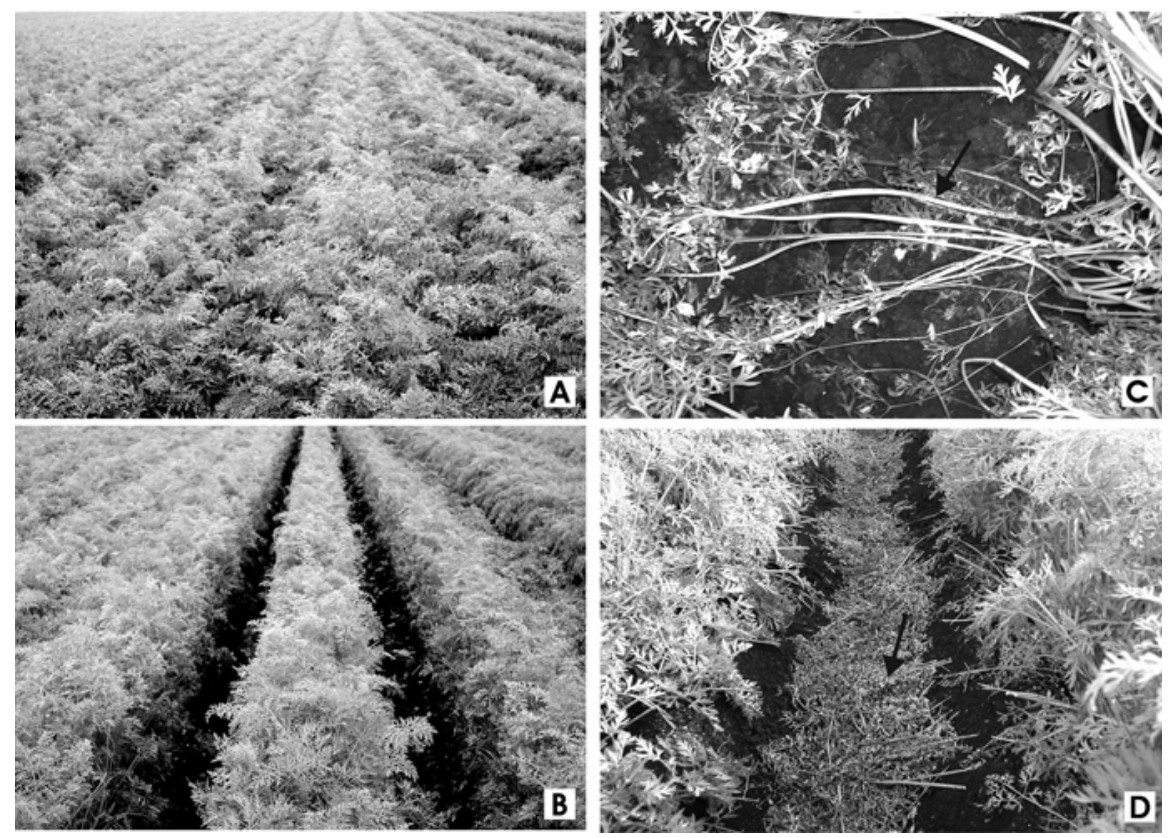

Fig. 2. Carrot crops with A, unclipped canopy and B, clipped with no debris in the furrow. C, Symptoms of Sclerotinia rot on lodged carrot leaves extending from crown to furrow under the unclipped canopy. D, Carrot crop clipped with foliar debris in the furrow 2 weeks after clipping. years had established a history of SRC epidemics. Carrot cv. Cellobunch was direct seeded with a precision seeder (90 to 100 seeds per meter) on raised trapezoid beds $86 \mathrm{~cm}$ apart center-to-center (Fig. 1) on 22 May 2001 and 23 May 2002. In each bed, three rows of carrots were seeded at ca. $5 \mathrm{~cm}$ apart. The experiments were arranged as completely randomized block designs with four canopy management treatments and four replications established in carrot plots measuring $35 \times 13.8$ $\mathrm{m}$ and $23 \times 13.8 \mathrm{~m}$ in 2001 and 2002, respectively. Each experimental plot consisted of four carrot beds of 8 and $6 \mathrm{~m}$ long each in 2001 and 2002, respectively. Sampling areas for assessing pathogen and yield variables were established in the two middle carrot beds and respective furrows of each experimental plot, allowing a 1-m guard zone on both ends of the bed. The plots were maintained following standard management recommendations (3), except that no fungicides were applied to the crop. Carrots were harvested on 30 October 2001 and 15 October 2002.

Canopy management treatments tested in these trials were: (i) unclipped control; (ii) unclipped canopy with manual removal of collapsed senescing leaves; (iii) lateral clipping with foliar debris left in the furrow; and (iv) lateral clipping with foliar debris removed from the furrow. The canopy in control plots was left untouched (Fig. 2A). The manual removal of collapsed senescing leaves treatment (ii) was performed at 2-week intervals starting when senescing leaves first appeared on the soil surface and continuing until harvest. Leaf removal started on 17 August 2001 and 16 August 2002, and culled leaves were left in the bottom of the furrow. Lateral clipping of carrot canopy in commercial crops is conducted using sets of rotating cutting blades and disks attached by hydraulic systems to the front and back of the tractor, respectively. In the present experiment, lateral clipping (treatments iii and iv) was reproduced using a gas operated hand-held hedge trimmer (STIHL HS45; Andreas Stihl AG \& Co. London, ON) with a 27-cc engine and 60$\mathrm{cm}$-long double-edge cutting blades. The clipping was conducted on 4 September 2001 and 30 August 2002, after initial apothecia of S. sclerotiorum were detected. Phenologically, the timing of clipping coincided with 10 to 20 days after the canopy closed and a growth stage of three to four senescing leaves per plant that were collapsed on the soil surface. The cutting blade of the trimmer was held vertically at ca. $85^{\circ}$ angle to the soil surface with the tip of the trimmer touching the soil approximately halfway down the slope of the bed ( 5 to $6 \mathrm{~cm}$ away from the bed shoulder; Fig. 1) and moved along parallel to the carrot rows. The operation aimed at cutting off ca. $20 \%$ of overlapping and lodged leaves above the furrow and collapsed 
senescing leaves on both sides of the carrot bed (Fig. 2B and D). The clipped foliar debris was left in the furrow (treatment iii) or removed manually from the furrow (treatment iv).

Assessment of the canopy. Variables of the canopy architecture, including canopy closure and lodging severity, were measured at weekly intervals from mid-July until harvest. Measurements of canopy width were recorded prior to and after clipping, and percent canopy coverage was estimated as the proportion of the canopy width over the bed width. The canopy was defined as closed when the foliage of carrots in adjacent beds touched and soil was no longer visible. Canopy lodging represented the number and the degree of contact of healthy leaves of carrot plants with the soil surface due to bending. Lodging was measured using a severity scale from 0 to 3 where: $0=$ no lodging, all leaves in an upright position; $1=1$ to 3 leaves per plant contacting the soil; $2=4$ to 5 leaves per plant laying on the soil; and $3=>5$ leaves per plant laying on the soil. Measurement of canopy lodging excluded the count of collapsed senescing leaves.

Assessment of microclimate. Air temperature, soil temperature, and relative humidity were monitored in one unclipped control plot and one clipped plot without debris using HOBO PRO RH/TEMP loggers (Onset Computer Co., Bourne, MA). Air temperature and relative humidity were recorded at $10 \mathrm{~cm}$ above soil surface in the furrow. Soil temperature was recorded by burying the HOBO loggers in the furrow at 5 -cm depth. The loggers were programmed to record readings every $30 \mathrm{~min}$ and installed in the field from the time of clipping to harvest. Rainfall was measured throughout the carrot growing season using a tipping bucket rain gauge Model TE525 (Campbell Scientific, Logan, UT) attached to a micrologger Model CR 21X (Campbell Scientific) installed in the carrot plot. The 30-min interval readings of air and soil temperatures and relative humidity, daily maximum air and soil temperatures, and daily minimum relative humidity were used to characterize the patterns of daily and seasonal differences between the microclimates in unclipped and clipped canopies.

Assessment of apothecia. The effect of canopy management on the development of S. sclerotiorum was evaluated by counting apothecia in the sampling area of each treatment plot. Scouting for apothecia was conducted at weekly intervals starting on 24 July 2001 and 16 July 2002, when the carrot canopy was about $50 \%$ closed, and continued until harvest. The presence of apothecia was recorded on every sampling date, but the number of apothecia in the sampling areas was counted only during periods of high apothecia production. Sampling areas included two 6- and 4-mlong furrows extending between the cen- ters of two adjacent carrot beds in 2001 and 2002, respectively (Fig. 1). The number of apothecia in the lateral clipping treatment with debris in the furrow included the apothecia underneath the debris, which were detected by lifting up the debris. The mean number of apothecia per meter on each sampling date was used for statistical analyses.

Assessment of disease. Incidence of SRC was determined at harvest as the percentage of carrot plants that had at least one diseased leaf or crown in 6- and 4-m sections of carrot bed in 2001 and 2002, respectively. Disease was assessed visually by identifying typical symptoms of SRC, including water-soaked, dark olive green lesions and actively growing mycelia or sclerotia of S. sclerotiorum. Diseased tissues that expressed symptoms of SRC were sampled regularly during the course of epidemics to confirm the presence of $S$. sclerotiorum. Leaf and petiole explants were surface-disinfested for $45 \mathrm{~s}$ in $70 \%$ ethanol, $1 \mathrm{~min}$ in $0.6 \%$ sodium hypochlorite, rinsed twice in sterile water, and plated onto Sclerotinia semi-selective medium of potato dextrose agar amended with $25 \mathrm{mg}$ of PCNB (75\% pentachloronitrobenzene), $150 \mathrm{mg}$ of penicillin G, 150 $\mathrm{mg}$ of streptomycin sulfate, and $50 \mathrm{mg}$ of bromophenol blue per liter (44). The presence of $S$. sclerotiorum was identified by the change of the medium color from blue to yellow, colony morphology, and sclerotia formation during 10 to 14 days of incubation at $21 \pm 1^{\circ} \mathrm{C}$.

Assessment of carrot yield. Fresh foliar and root weights at harvest were used to assess the effect of canopy clipping on the development and yield of carrot. Carrots were harvested from 2-m sample sections of the bed. Tops were weighed separately from the roots, and mean foliar and root weights per meter of carrot bed were used for statistical analyses.

Statistical analyses. Variance and residual analyses were performed on the number of apothecia, fresh foliar weight, and fresh root weight. When the normality and homogeneity assumptions for residuals were not met, the data were subjected to $\log$ or arcsine square root transformation. Mean comparisons among individual treatments were performed using Fisher's least significant difference tests. In addition, orthogonal contrast analyses were performed on the number of apothecia after canopy clipping to compare the grouped clipped versus unclipped treatments. Results from separate trials were not combined if significant treatment-byyear interactions were detected. A paired $t$ test was performed on the mean differences between the daily maximum (air and soil temperature) or minimum (relative humidity) values in clipped and unclipped plots. Graphical plotting of these differences against daily rainfall and maximum ambient air temperature was used to exam- ine the effect of canopy clipping under varying weather patterns. Statistical analyses were performed using Proc GLM (general linear model) and Proc ttest procedures of SAS (SAS Institute, Cary, NC).

\section{RESULTS}

Weather conditions during the growing season in 2001 differed from those of 2002. Year 2001 was characterized by a relatively dry summer, with frequent rainfall starting mid-September through October. In 2002, rainfall was high during early summer, while late summer and fall were relatively dry. Varying weather patterns were associated with variations in the abundance of apothecia, occurrence of disease, and the effect of canopy clipping on microclimate variables. However, the overall patterns of effects of canopy management were consistent across the years.

Effect of canopy management on canopy architecture. Lateral clipping was conducted shortly after the initial detection of apothecia, which occurred after the carrot canopy had closed. As a result of clipping, an average of 3 of 10 healthy leaves per carrot plant in the outer rows of beds were severed to petioles that were 20 to $23 \mathrm{~cm}$ in length. The canopy width was reduced to $52 \pm 2 \mathrm{~cm}$, which was ca. $60 \%$ of the original width. Consequently, an open area of $34 \pm 2 \mathrm{~cm}$ remained between canopies of adjacent beds and ca. $40 \%$ of the furrow was exposed (Fig. 1). An average of $11.9-\mathrm{cm}$ increase in canopy width occurred on each side of the bed as a result of continuous growth of central leaves during the 8- to 9-week periods elapsing from clipping to harvest; however, clipped canopies did not re-close.

Canopy lodging was measured to assess the effect of canopy management on plantto-soil contact. Prior to clipping, the lodging severity of carrot canopies in both years was at level 2, i.e., four to five healthy leaves per carrot plant were bending over the furrow and laying on the soil. Lateral clipping completely removed the lodged portion of healthy leaves and reduced lodging severity to 0 for the remaining period until harvest. In canopies that did not receive the clipping treatment, lodging progressed continuously, reaching a maximum severity of 3 by midSeptember. In addition, clipping cut off most of the senescing leaves that had accumulated on the soil at the time of the clipping operation. Occasionally, new senescing leaves collapsed on the soil after clipping, but these readily desiccated due to sunlight exposure. Foliar debris left in the furrow after clipping desiccated in 7 to 10 days depending on environmental conditions, and was soon reduced to a thin layer of decomposing leaves (Fig. 2D).

Effect of canopy management on microclimate. On average, air and soil temperatures were lower and relative humidity was higher in unclipped canopies com- 
pared with clipped canopies in both years. During the day, air temperature under the unclipped canopy was lower in the afternoon and slightly higher during the night
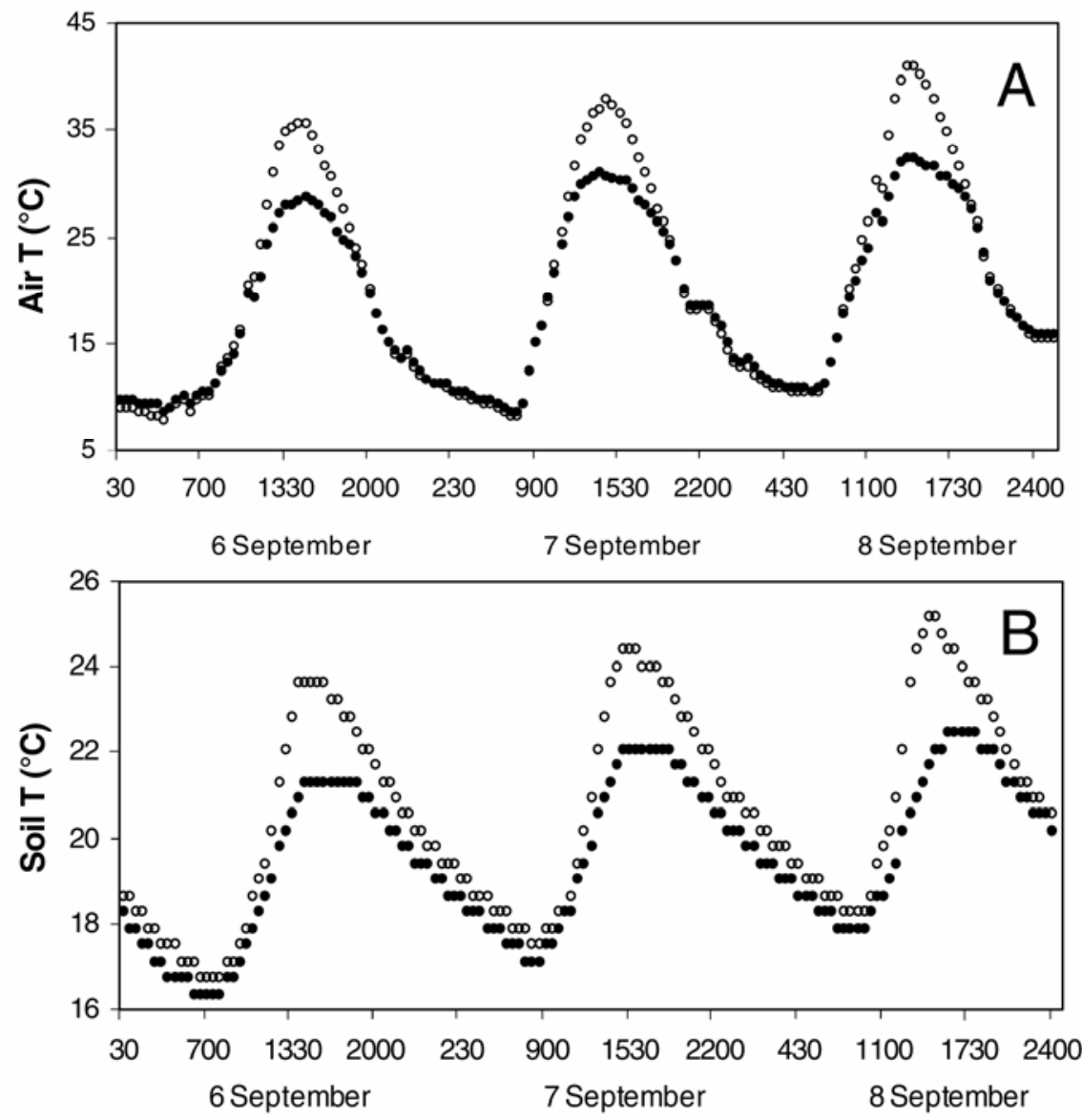

Time of day (h) and date

Fig. 3. Thirty-minute interval recordings of $\mathbf{A}$, air temperature $(\mathrm{T})$ and $\mathbf{B}$, soil $\mathrm{T}$ during a 3-day sample period in clipped (open circles) and unclipped (closed circles) canopies in experimental carrot crops in 2002. Air and soil $\mathrm{T}$ were recorded at $10 \mathrm{~cm}$ above soil surface and $5 \mathrm{~cm}$ below soil surface in the furrows of one clipped and one unclipped canopy, respectively. Clipped canopies were laterally reduced to ca. $60 \%$ of the original width and had $40 \%$ of the furrow exposed; unclipped canopies were closed and had shaded furrows.

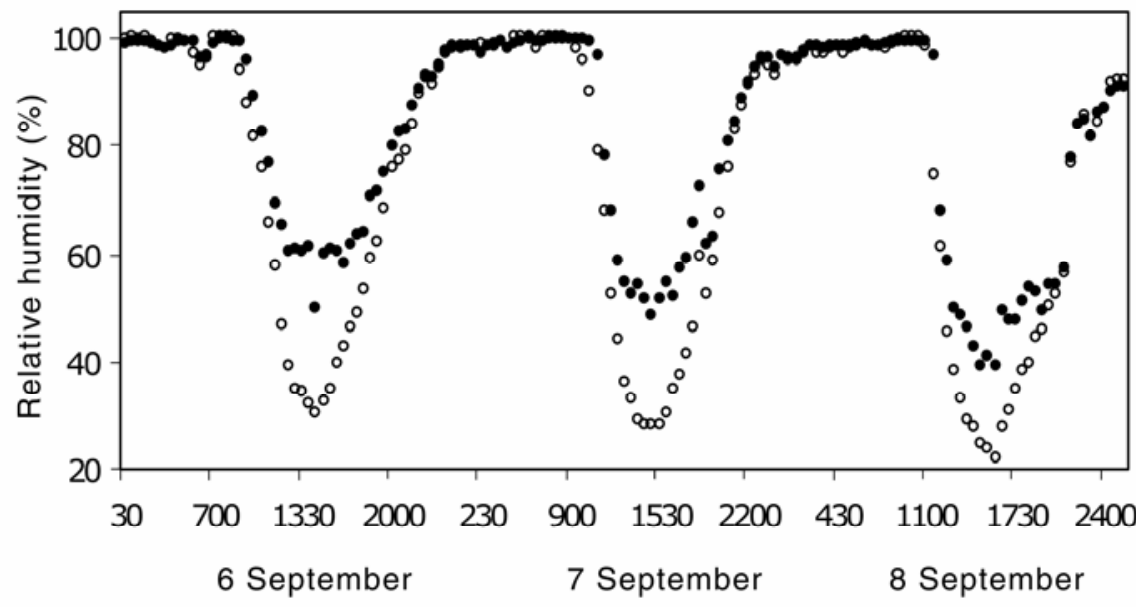

Time of day (h) and date

Fig. 4. Thirty-minute interval recordings of relative humidity during a 3-day sample period at $10 \mathrm{~cm}$ above the soil level in the furrows of one clipped (open circles) and one unclipped (closed circles) canopy of carrot crops in 2002. Clipped canopies were laterally reduced to ca. $60 \%$ of the original width and had $40 \%$ of the furrow exposed; unclipped canopies were closed and had shaded furrows. unclipped canopy than in the clipped canopy (Fig. 3). Relative humidity under the unclipped canopy was usually higher during late morning and afternoon, but was similar to the clipped canopy during the night (Fig. 4). Typically, differences between microclimate variables in unclipped and clipped canopies reached their maxima in the afternoon, when these variables reached their daily peaks.

During the assessment period from clipping to harvest, mean maximum air temperature in 2001 was 17.9 and $16.8^{\circ} \mathrm{C}$ in the clipped and unclipped canopies, respectively, with daily differences ranging from -0.2 to $3.1^{\circ} \mathrm{C}(P=0.0001)$ (Fig. 5, Table 1). (Note: positive differences indicate higher variable values in the clipped canopy compared with the unclipped canopy; negative differences indicate lower variable values in the clipped canopy). In 2002, mean maximum air temperature was 26.2 and $23.9^{\circ} \mathrm{C}$ in the clipped and unclipped canopies, respectively, with daily differences ranging from -0.8 to $9.2^{\circ} \mathrm{C}$ ( $P$ $=0.0001)$ (Fig. 6, Table 1). The difference between daily minimum relative humidity in clipped and unclipped canopies ranged from -19.1 to $-2.0 \%(P=0.0001)$ and -30.0 to $6.1 \%(P=0.0005)$ in 2001 and 2002, respectively (Figs. 5 and 6, Table 1). The difference between daily maximum soil temperatures in the clipped and unclipped canopies ranged from -1.5 to $3.1^{\circ} \mathrm{C}$ in $2002(P=0.0003)$ (Fig. 7 , Table 1). Soil temperature data were not available for 2001 because of technical failure of the HOBO loggers. Similar to daily variations, seasonal differences between microclimate variables in clipped and unclipped canopies were usually higher during peak periods of hot and dry weather. The difference between maximum air temperatures increased substantially when maximum ambient temperature was above $25^{\circ} \mathrm{C}$, and was highest at above $30^{\circ} \mathrm{C}$. The difference between minimum relative humidities increased when ambient relative humidity was below $90 \%$ and was highest at below $80 \%$. In general, during periods of high rainfall and cool weather, microclimate differences were minimal. However, this pattern was not observed for relative humidity during the end of the 2001 assessment period.

Effect of canopy management on development of apothecia of $S$. sclerotiorum. In 2001, apothecia were observed 1 week earlier and were on average sixfold more abundant than in 2002 (Fig. $8)$. In 2001, apothecia were initially detected at low numbers on 21 and 27 August (days 232 and 239). During the following 3 -week period, apothecia were not observed, probably because of prevailing dry weather. Apothecia reappeared on 24 September (day 267) and were present until 30 October (day 303), when the crop was harvested. The mean number of apothecia counted on days 282,289 , and 296 was 1.2 
apothecia per meter, reaching a maximum of 4.1 apothecia per meter on 23 October (day 296). In 2002, apothecia were first detected on 27 August (day 239) and were consistently observed in the crop until 9 October (day 282). The mean number of apothecia counted on days 239, 246, 253, 260, 267, and 274 was 0.2 apothecia per meter, reaching a maximum of 1.9 apothecia per meter on 1 October (day 274). Initial emergence of apothecia followed accumulations of 36 and $26 \mathrm{~mm}$ of rainfall during the preceding week in 2001 and 2002, respectively. During the periods when apothecia were present, there were totals of 134.8 and $85.3 \mathrm{~mm}$ of rainfall in the plots in 2001 and 2002, respectively. Average air temperatures during these periods were 12.9 and $15.3^{\circ} \mathrm{C}$, respectively.

Overall, the number of apothecia in clipped plots was lower compared with unclipped plots in 2001 and 2002, respectively (Table 2). Orthogonal contrast analyses indicated that the differences between the numbers of apothecia in clipped and unclipped plots were -1.4 and -0.2 apothecia per meter in $2001(P=$ $0.0001)$ and $2002(P=0.0018)$, respectively. Consequently, clipping reduced the quantity of apothecia by 74 and $76 \%$ in 2001 and 2002, respectively. The number of apothecia in clipped plots with debris in the furrow was higher than in the plots without debris in 2001, but not in 2002 . Significant differences in the number of apothecia among canopy management treatments were observed on each assessment day during 2001 (Fig. 8). In 2002, these differences were observed only on 24 September (day 267) and 1 October (day 274). Data could not be pooled over 2001 and 2002 because of significant treatmentby-year interactions. In clipped plots, apothecia always appeared localized in shaded areas, such as under the reduced canopy on top of carrot beds, and occasionally under the clipped debris in the furrow. In contrast, apothecia were found throughout unclipped plots, including on bed tops, slopes, and furrow depressions.

Effect of canopy management on the development of disease. Sclerotinia rot was first observed on 2 October 2001. The epidemic started after apothecia appeared within the crop and after the onset of foliar senescence, and followed $23.5 \mathrm{~mm}$ of rainfall during the preceding week. Disease developed on carrot leaves in all unclipped plots, including controls and plots where collapsed senescing leaves were removed manually, reaching 14.5 and $17.7 \%$ incidence at harvest (Table 2). Localized lesions observed at the start of the epidemic soon expanded over entire leaves and petioles. Mycelia of S. sclerotiorum appeared over the lesions and spread rapidly upon contact with adjacent leaves of neighboring plants (Fig. 2C). However, only a few carrot plants were observed with sympto- matic diseased crowns or collapsed tops. In contrast, no disease developed in carrot plots where the canopies were laterally clipped. In 2002, disease did not develop in any of the treatments.

Effect of canopy management on carrot yield. No differences were observed between the fresh foliar weight and fresh root weight of carrots at harvest in clipped and unclipped plots under these test conditions (Table 2).

\section{DISCUSSION}

The purpose of this study was to evaluate the efficacy of manipulating the carrot canopy in an effort to suppress the development of S. sclerotiorum and to manage SRC in the field. Results demonstrated that architectural and phenological attributes of carrots, including canopy closure and foliar senescence, were important factors for the development of apothecia of $S$. sclerotiorum and epidemics of SRC. Lateral clipping modified the canopy architecture and the microclimate, and reduced the quantity of apothecia in carrot crops. In addition, lateral clipping appeared to completely control SRC where it occurred (in 2001). However, consistent control of SRC using this technique could not be demon-

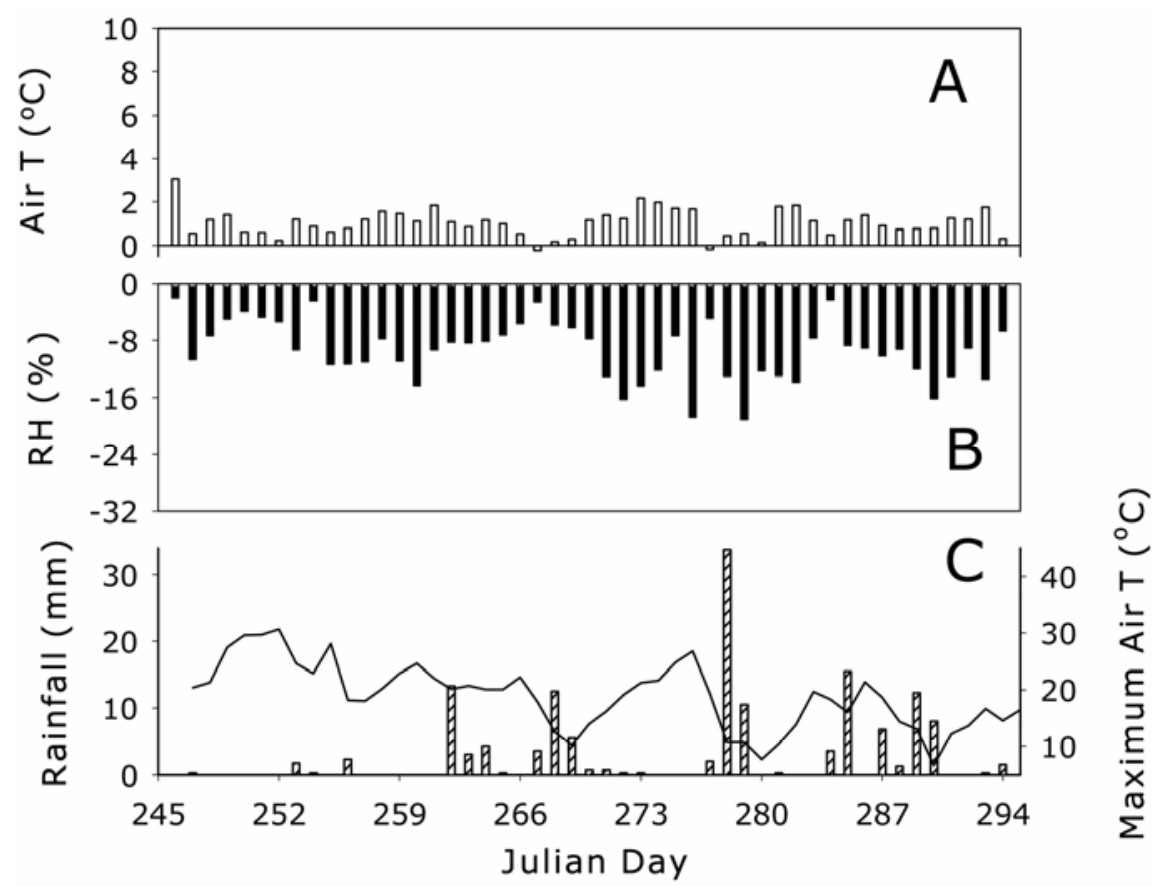

Fig. 5. Differences of $\mathbf{A}$, maximum daily air temperature (T) and $\mathbf{B}$, minimum relative humidity (RH) between one clipped and one unclipped carrot canopy at $10 \mathrm{~cm}$ above the soil, and $\mathbf{C}$, daily rainfall (patterned bars) and daily ambient maximum air T (solid line) during day 247 to 294 (4 September to 21 October) in 2001. Positive differences indicate that variables were higher in the clipped canopy compared with the unclipped canopy, and negative differences indicate lower values in the clipped canopy. Clipped canopies were laterally reduced to ca. $60 \%$ of the original width and had $40 \%$ of the furrow exposed; unclipped canopies were closed and had shaded furrows.

Table 1. Effect of lateral clipping of carrot canopy on maximum air temperature (T), minimum relative humidity (RH), and maximum soil $\mathrm{T}$ in experimental carrot crops in Bradford Marsh, Ontario, in 2001 and 2002

\begin{tabular}{|c|c|c|c|c|c|}
\hline \multirow[b]{2}{*}{ Variable } & \multirow[b]{2}{*}{ Year } & \multirow[b]{2}{*}{ Mean difference ${ }^{x}$} & \multirow[b]{2}{*}{ Range of difference ${ }^{y}$} & \multicolumn{2}{|c|}{ Paired $t$ test $^{\mathrm{z}}$} \\
\hline & & & & $t$ value & $P>|\mathbf{T}|$ \\
\hline \multirow[t]{2}{*}{ Air $\mathrm{T}\left({ }^{\circ} \mathrm{C}\right)$} & 2001 & $1.0 \pm 0.09$ & -0.2 to 3.1 & 11.5 & 0.0001 \\
\hline & 2002 & $2.3 \pm 0.36$ & -0.8 to 9.2 & 6.4 & 0.0001 \\
\hline \multirow{2}{*}{$\mathrm{RH}(\%)$} & 2001 & $-9.5 \pm 0.59$ & -19.1 to -2.0 & -16 & 0.0001 \\
\hline & 2002 & $-7.3 \pm 1.17$ & -30.0 to 6.1 & -6.2 & 0.0005 \\
\hline \multirow{2}{*}{ Soil T $\left({ }^{\circ} \mathrm{C}\right)$} & 2001 & NA & NA & NA & NA \\
\hline & 2002 & $0.7 \pm 0.18$ & -1.5 to 3.1 & 3.9 & 0.0003 \\
\hline
\end{tabular}

${ }^{\mathrm{x}}$ Mean difference between daily maximum (air and soil T) or minimum (RH) values in clipped vs. unclipped canopies during 58 (2001) and 43 (2002) days following the lateral clipping \pm standard error of the mean. $\mathrm{NA}=$ data not available.

${ }^{y}$ Minimal and maximal differences between daily maximum (air and soil $\mathrm{T}$ ) or minimum (RH) values in clipped vs. unclipped canopies.

${ }^{\mathrm{z}}$ Paired $t$ test analyses tested whether the mean differences of variables between clipped and unclipped canopies were different from zero at level of significance $\alpha=0.05$. The null hypothesis (difference $=$ 0 ) is rejected if $P>|\mathrm{T}|$ is $<0.05$. 
strated because disease was not observed in the second year of this study.

In canopies opened by lateral clipping, air and soil temperatures were usually higher and relative humidity was lower than under closed canopies. These differences were at their maxima when respective variables reached their daily or sea-
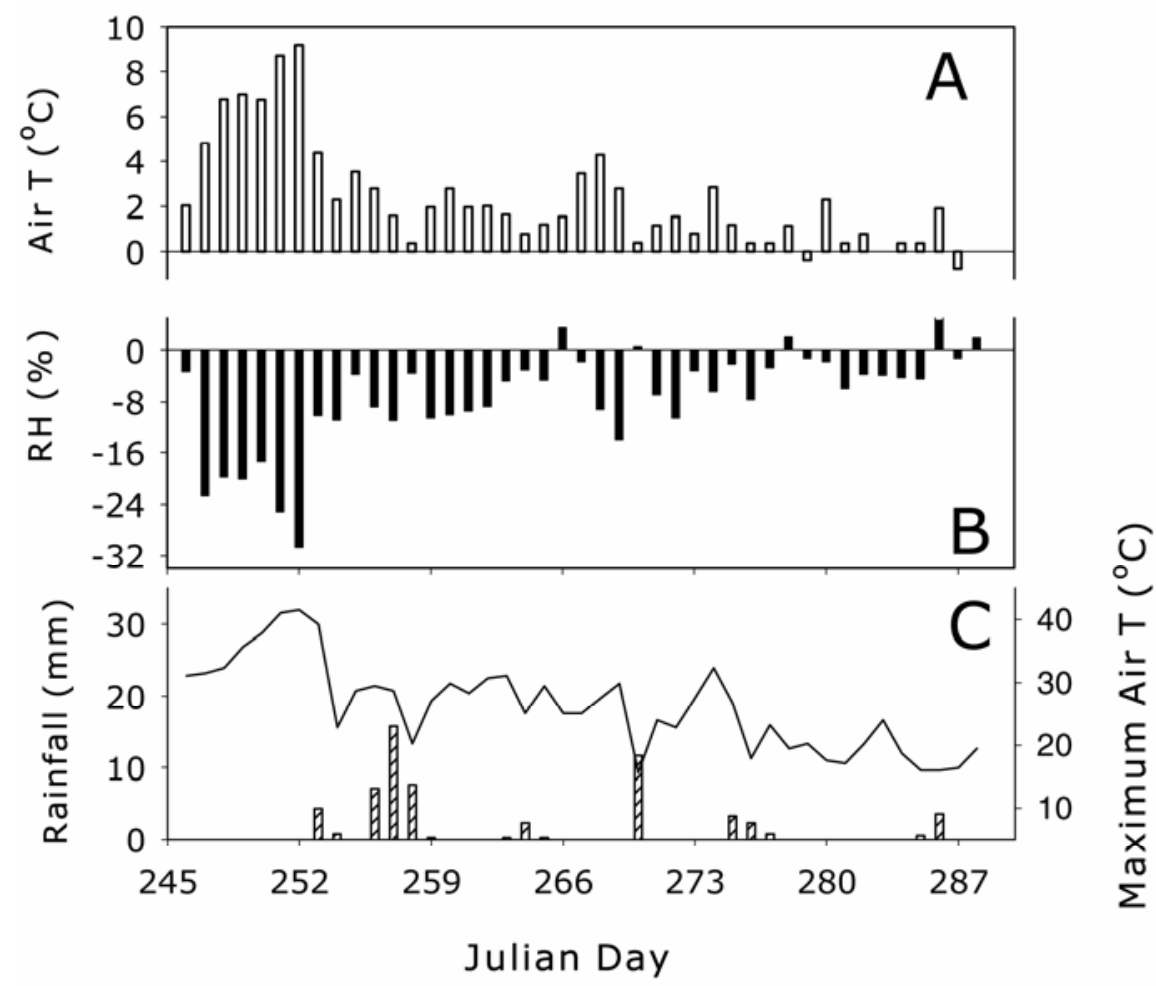

Fig. 6. Differences of A, maximum daily air temperature (T) and $\mathbf{B}$, minimum relative humidity (RH) between one clipped and one unclipped carrot canopy at $10 \mathrm{~cm}$ above the soil, and $\mathbf{C}$, daily rainfall (patterned bars) and daily ambient maximum air T (solid line) during day 246 to 288 (3 September to 15 October) in 2002. Positive differences indicate that variables were higher in the clipped canopy compared with the unclipped canopy, and negative differences indicate lower values in the clipped canopy. Clipped canopies were laterally reduced to ca. $60 \%$ of the original width and had $40 \%$ of the furrow exposed; unclipped canopies were closed and had shaded furrows.
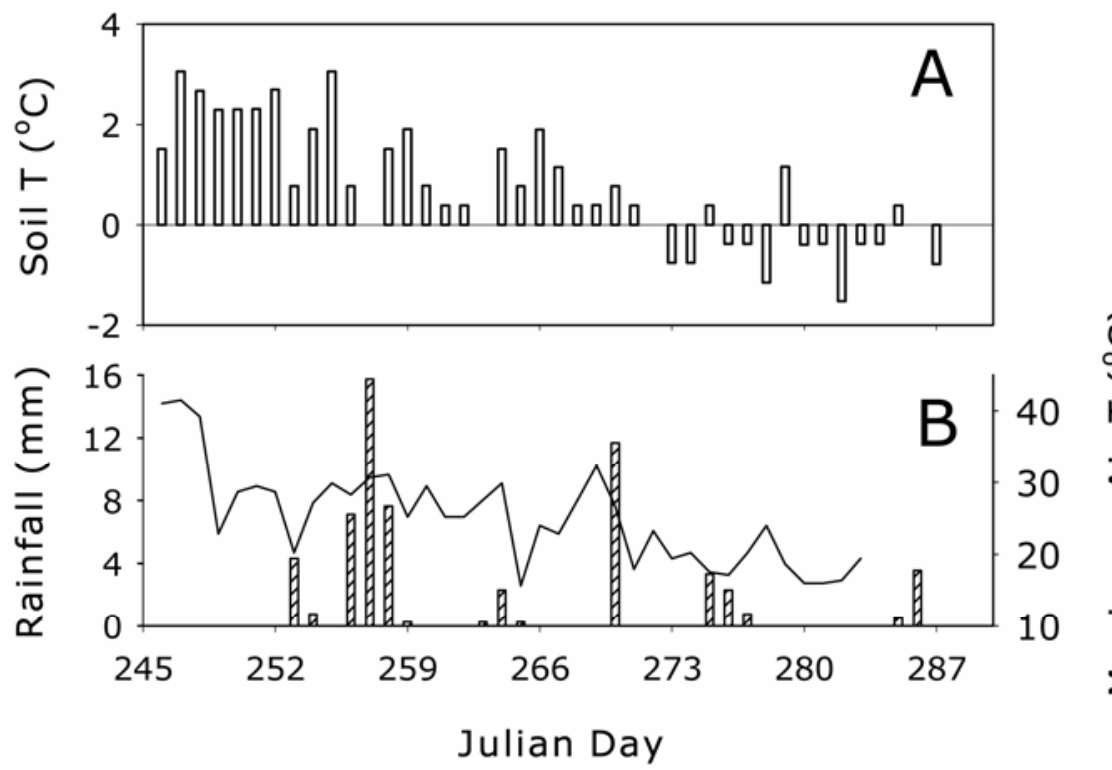

Fig. 7. Differences of A, maximum daily soil temperatures (T) at $5 \mathrm{~cm}$ below soil surface in the furrows of one clipped and one unclipped carrot canopy, and $\mathbf{B}$, daily rainfall (patterned bars) and maximum ambient air T (solid line) during day 246 to 288 (3 September to 15 October) in 2002. Positive differences indicate soil $\mathrm{T}$ higher in the clipped canopy compared with the unclipped canopy, and negative differences indicate lower $\mathrm{T}$ in the clipped canopy. Clipped canopies were laterally reduced to ca. $60 \%$ of the original width and had $40 \%$ of the furrow exposed; unclipped canopies were closed and had shaded furrows.

sonal peaks, demonstrating the buffering effect of a closed canopy on microclimate fluctuations. Warmer and dryer microclimates in exposed canopies probably resulted from improved air circulation and direct light penetration. The attenuating pattern of these differences toward the end of the season, particularly in 2002, may be explained by more porous canopies due, in part, to aging and foliar damage by Alternaria (Alternaria dauci (Kühn)) and Cercospora (Cercospora carotae (Pass.)) leaf blights. The results of this study are consistent with the effects of canopy architecture on the microclimate and Sclerotinia disease obtained in other crops (25). Air temperature under the bean canopy was lower in the afternoon and higher during the night compared with exposed canopies $(12,16)$. Bare soil and soil under pruned peanut canopies had higher temperatures than under an unpruned canopy, except during rain periods (11). Crops of bean cultivars with a dense and prostrate canopy had lower air and soil temperature, higher soil moisture, and higher severity of white mold compared with cultivars with a less dense and open canopy $(4,16,52)$. The effect of canopy clipping on the duration of surface wetness on bottom carrot leaves or soil moisture was not assessed in the present study. However, results from earlier epidemiological studies in carrots (27) and other crops $(4,11,16,52)$ suggest that increased light penetration and air flow are likely to encourage evaporation and moisture loss from foliar and soil surfaces in carrot crops. The spacing of carrot beds in this study was set at $86 \mathrm{~cm}$ to accommodate the cultivation system practiced at the experimental station and some commercial fields in the area. Spacing of carrot rows or beds may differ, and where narrower spacing is used, new foliar growth may result in reclosure of the canopy sometime after the clipping. However, it is unlikely that the canopies will relodge, because clipping removes most leaves with potential to lodge and senesce.

The modified microclimate associated with clipped canopies was important in suppressing the development of apothecia in carrot plots. Carpogenic germination of sclerotia requires prolonged periods of high soil moisture and cool temperature, and can be prevented by even slight changes in soil moisture $(1,26,30,41,49)$. Lower air temperatures under a dense canopy can also promote survival and germination of ascospores on the leaf surface (12). The closed carrot canopy over the soil appeared to create favorable conditions for the development of S. sclerotiorum by maintaining prolonged cool and humid conditions and preventing extreme temperatures. These results agree with previous reports where emergence of apothecia occurred after the development of a closed canopy in carrots $(14,22,28)$ and other crops $(7,33,41)$. The lower num- 
ber of apothecia observed in carrot crops in 2002 may have been attributed, in part, to the prevailing dry and hot weather during the emergence of apothecia. By reducing the number of apothecia, lateral clipping reduced the amount of inoculum produced in the field. Production of within-field ascospores is a critical event in the epidemiology of preharvest epidemics of SRC (27) and Sclerotinia diseases in other crops $(8,9,33)$. Therefore, the management of internal inoculum is an important aspect in the management of disease.

The presence of clipped foliar debris in the furrow appeared to affect the number of apothecia within the crop in 2001, partly because a number of apothecia were observed under the debris. However, apothecia that develop under the debris are unlikely to contribute to the overall inoculum in the crop because the debris layer can obstruct the discharge of ascospores. Mulching of the soil surface may act as a physical barrier and, therefore, suppress carpogenic germination of sclerotia. A layer of $6 \mathrm{~cm}$ of dry grass (Pennisetum purpureum L.) reduced the number of apothecia in bean crops by $48 \%$ due to failure of stipes to rise above the soil surface and reduced light radiation under the mulch (18). The removal of foliar debris from the furrow after clipping resulted in the highest suppression of apothecia, but it is impractical and unlikely to be applied commercially. The results of contrast
Table 2. Effect of canopy management on number of apothecia of Sclerotinia sclerotiorum, incidence of Sclerotinia rot of carrot, fresh foliar weight, and fresh root weight in carrot crops in Bradford Marsh, Ontario, in 2001 and 2002

\begin{tabular}{lcc}
\hline & \multicolumn{2}{c}{ Year } \\
\cline { 2 - 3 } Treatment & $\mathbf{2 0 0 1}$ & $\mathbf{2 0 0 2}$ \\
\hline & \multicolumn{2}{c}{ Apothecia/m $^{\mathrm{w}}$} \\
Unclipped control & $1.5 \mathrm{a}^{\mathrm{x}}$ & $0.3 \mathrm{a}$ \\
Unclipped/manual removal of senescing leaves & $1.7 \mathrm{a}$ & $0.2 \mathrm{a}$ \\
Clipped with debris in furrow & $0.6 \mathrm{~b}$ & $0.08 \mathrm{~b}$ \\
Clipped with no debris in furrow & $0.3 \mathrm{c}$ & $0.04 \mathrm{~b}$ \\
& Disease incidence & $\mathbf{( \% )}$ \\
Unclipped control & $14.5 \mathrm{~b}$ & - \\
Unclipped/manual removal of senescing leaves & $17.7 \mathrm{a}$ & - \\
Clipped with debris in furrow & $0 \mathrm{c}$ & - \\
Clipped with no debris in furrow & $0 \mathrm{c}$ & - \\
& Fresh foliar weight & $(\mathbf{k g} / \mathbf{m})$ \\
Unclipped control & $0.9 \mathrm{a}$ & $0.9 \mathrm{a}$ \\
Unclipped/manual removal of senescing leaves & $1.1 \mathrm{a}$ & $0.8 \mathrm{a}$ \\
Clipped with debris in furrow & $1.0 \mathrm{a}$ & $0.8 \mathrm{a}$ \\
Clipped with no debris in furrow & $0.9 \mathrm{a}$ & $0.8 \mathrm{a}$ \\
& Fresh root weight ${ }^{\mathrm{z}}(\mathbf{k g} / \mathbf{m})$ \\
Unclipped control & $7.4 \mathrm{a}$ & $7.7 \mathrm{a}$ \\
Unclipped/manual removal of senescing leaves & $8.8 \mathrm{a}$ & $7.2 \mathrm{a}$ \\
Clipped with debris in furrow & $8.1 \mathrm{a}$ & $6.6 \mathrm{a}$ \\
Clipped with no debris in furrow & $7.4 \mathrm{a}$ & $6.6 \mathrm{a}$
\end{tabular}

${ }^{\text {w}}$ Mean number of apothecia in two 6- and 4-m sample sections of four replications over $3(\mathrm{~N}=48)$ and $5(\mathrm{~N}=80)$ weeks following treatments in 2001 and 2002, respectively. Statistics were performed on log-transformed data; reported means represent back-transformed values.

${ }^{x}$ Numbers in columns within each variable followed by the same letter are not significantly different $(P \geq 0.05$, Fisher's protected LSD test).

${ }^{y}$ Mean percentage of plants with diseased foliage in 6-m (2001) and 4-m (2002) carrot beds of four replications at harvest $(\mathrm{N}=16)$. Statistics were performed on arcsine square root transformed data; reported means represent back-transformed values. $-=$ disease not observed in these plots.

${ }^{\mathrm{z}}$ Mean foliar or root weight of carrots sampled from 2-m sections of carrot bed of four replications at harvest $(\mathrm{N}=16)$.

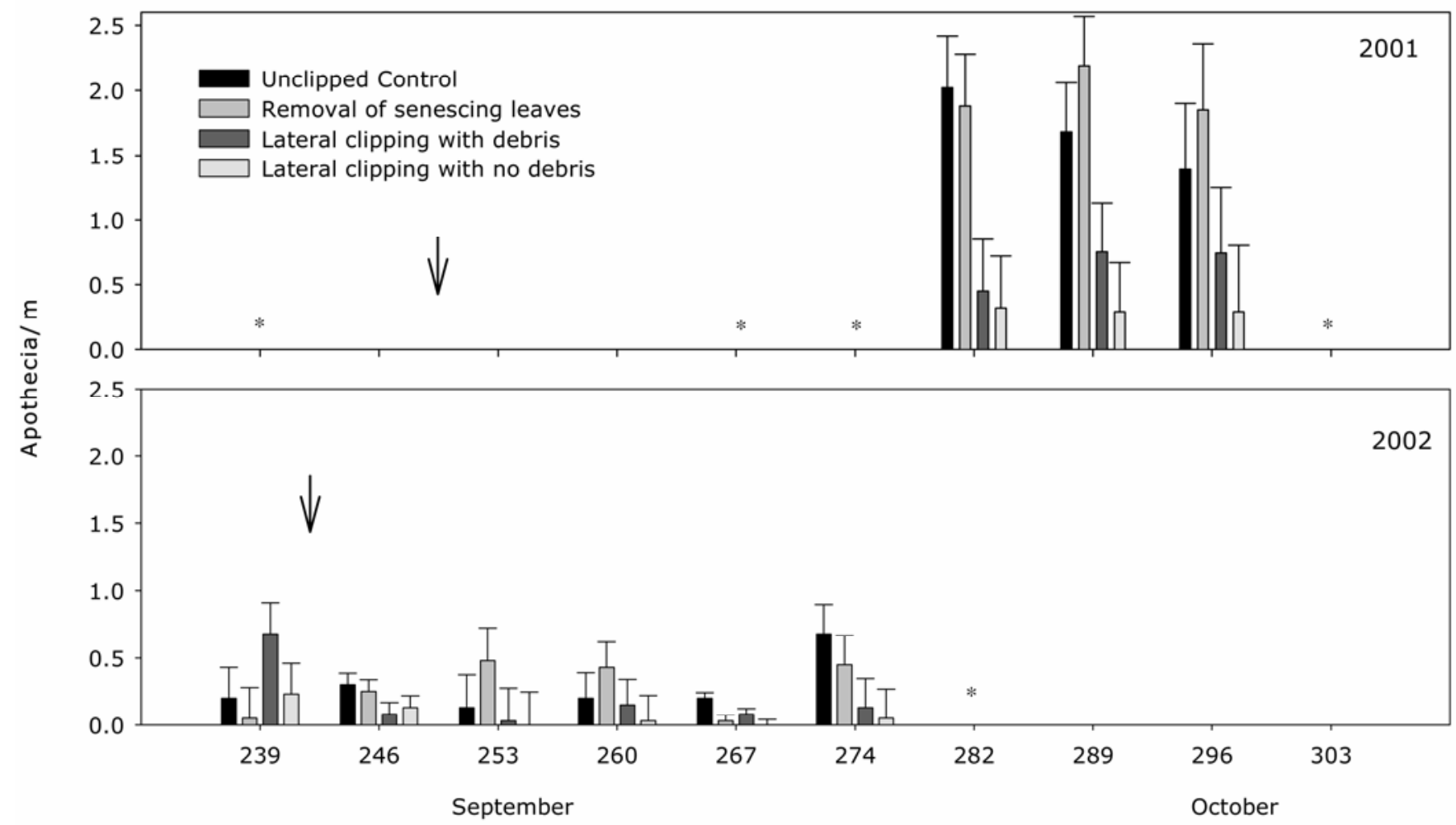

Julian Day

Fig. 8. Effect of canopy management on number of apothecia of Sclerotinia sclerotiorum in experimental carrot crops during day 239 to 303 (27 September to 30 October) in 2001 and 2002. Clipped canopies were laterally reduced to ca. $60 \%$ of the original width and had $40 \%$ of the furrow exposed; unclipped canopies were closed and had shaded furrows. Arrows indicate timing of clipping operations. *Apothecia were present but not counted. 
analyses suggest that the presence of foliar debris in the furrow does not affect the overall benefits of clipping in reducing inoculum and disease. Conducting the clipping during dry weather will encourage rapid desiccation of the foliar debris.

The absence of disease in plots with clipped canopies in 2001 was attributed, in part, to the removal of senescing leaves and lodging portions from the carrot plants. Foliar senescence marks the susceptible stage in the phenology of carrot, and senescing leaves on the soil are an essential substrate for the initiation of epidemics. By cutting off senescing and lodging leaves, clipping removes potential infection sites and minimizes plant-to-soil and plant-to-plant contact. In contrast, extended periods of higher humidity, in addition to increasing amounts of senescing tissues accumulated in the furrow, may explain increased levels of disease in closed canopies. The presence of foliar disease in the plots where senescing leaves were removed manually suggested that canopy lodging is important in the development of the disease because it allows contact of healthy leaves with infested plant material in the furrow. Clipping of the canopy may have contributed to avoidance of SRC by reducing the amount of susceptible tissue available for infection to occur, and by rendering the conditions unfavorable for disease to develop. Similarly, mechanical manipulation of the canopy reduced apothecia production and severity of Sclerotinia diseases in other crops $(11,37)$. These effects were attributed to less favorable conditions for pathogen growth created by the open canopy, removal of potential infection sites, or improved penetration of fungicides to infection sites. Absence of foliar disease in 2002 may have been a result of the lower number of apothecia within the crop and the relatively dry and hot weather conditions during late summer and fall. Similarly, in the surrounding commercial carrot crops, SRC epidemics were either not observed or unimportant.

Lateral clipping is optimal when it achieves maximum suppression of the pathogen and disease with minimal disruption of carrot development. Therefore, appropriate timing of clipping is critical and must take into consideration important events in the growth of carrot in addition to the life cycle of $S$. sclerotiorum. Along with senescing foliage, lateral clipping usually removes considerable portions of photosynthetically active leaves and may affect the size and weight of roots. Yield reduction following trimming as a result of the loss of active leaves has been an occasional concern in peanut, particularly under low disease pressure (11). Clipping did not affect carrot yield under the test conditions in this study; however, yield reduction may occur if the clipping is excessive or conducted during critical stages of carrot growth.
Studies on carrot growth and developmental patterns demonstrated that taproot elongation progresses rapidly during the first 3 to 4 weeks of growth (53), and the enlargement of the fleshy storage organ usually starts after 6 weeks of growth (17). In winter-grown (e.g., October to February) carrots in Florida, foliar and root weights and root length increased steadily during the first 90 to 100 days after seeding (DAS); after that, root growth continued at a lower and variable rate until 120 DAS (45). In summer-grown (e.g., May to October) carrots in Finland, foliar weight and leaf area reached their maxima at 90 to 130 DAS; however, root yield increased by 10 to $36 \%$ from early September until harvest in late October (ca. 160 DAS) $(47,48)$. These studies suggest that most of the photosynthetic capacity and at least $75 \%$ of root weight are established within the first 90 to 100 DAS, and significant root growth can occur after 100 DAS. The clipping of carrot canopy in this study was primarily targeted at disrupting the development of the pathogen. S. sclerotiorum is most vulnerable to environmental conditions during carpogenic and myceliogenic germination, when moisture and temperature become important limiting factors. Interruption of this particular stage of the pathogen life cycle can effectively reduce inoculum production; therefore, clipping was timed at the early stages of apothecia detection. Following this critical point, clipping coincided with 105 and 100 DAS in 2001 and 2002, respectively. Canopy clipping may have interfered with weight increase later in the season, but it did not significantly reduce fresh foliar and root weights of carrot.

The use of initial emergence of apothecia as an indicator for timing the clipping was effective in this study. Similarly, in clover crops, foliar clipping was effective when applied before abundant development of apothecia and counter-effective when applied after symptoms of Sclerotinia crown and stem rot were detected (37). However, there are a number of limitations associated with using the emergence of apothecia as a criterion for timing the clipping. Monitoring for apothecia in commercial fields can be laborious and time-consuming. In addition, the occurrence of apothecia is sporadic in time and space $(8-10,33)$, and even when present, detection of apothecia can be obstructed by their aggregated distribution and the sample size. The number of apothecia within treatments in this experiment was highly variable. Spatial aggregation may also be a pattern of apothecia distribution in carrot crops, as reported in bean and soybean fields $(5,6)$, explaining at least some of the variability within treatments. More research is needed to explore alternative options for timing the canopy clipping when emergence of apothecia cannot be used as a criterion and to study the effects of multiple clippings conducted over a wider range of carrot growth stages.

Although disease control benefits of canopy clipping could not be conclusively substantiated, this study offers an important cultural option for the management of SRC through the reduction of inoculum and potential infection sites. Incorporating canopy clipping into an integrated system may substantially improve the management of the disease in both conventional and organic carrot production. Additional research on the economic feasibility of this practice may contribute to the rapid adoption of canopy clipping by carrot growers.

\section{ACKNOWLEDGMENTS}

We thank the Natural Sciences and Engineering Research Council of Canada (NSERC), Ontario Ministry of Agriculture and Food (OMAF), Ontario Fruit and Vegetable Growers Association (OFVGA), and Bradford and District Vegetable Growers Association (BDVGA) for providing the funding for this project. We also thank Todd Crosby (Mercer Ranch, WA) for consultations on the commercial application of lateral clipping and Kevin Vander Kooi (Muck Crops Research Station, Bradford Marsh, Ontario) for technical assistance.

\section{LITERATURE CITED}

1. Abawi, G. S., and Grogan, R. G. 1979. Epidemiology of diseases caused by Sclerotinia species. Phytopathology 69:899-904.

2. Anonymous. 1970. Carrot. Can. Plant Dis. Surv. 50:20.

3. Anonymous. 2000. Carrots. Pages 70-73 in: Vegetable Production Recommendations, 2000-2001. Publ. 363. Ontario Ministry of Agriculture, Food and Rural Affairs, Guelph, Ontario.

4. Blad, B. L., Steadman, J. R., and Weiss, A. 1978. Canopy structure and irrigation influence white mold disease and microclimate of dry edible beans. Phytopathology 68:14311437.

5. Boland, G. J., and Hall, R. 1986. Growthroom evaluation of soybean cultivars for resistance to Sclerotinia sclerotiorum. Can. J. Plant Sci. 66:559-564.

6. Boland, G. J., and Hall, R. 1987. Evaluating soybean cultivars for resistance to Sclerotinia sclerotiorum under field conditions. Plant Dis. 71:934-936.

7. Boland, G. J., and Hall, R. 1988. Epidemiology of Sclerotinia stem rot of soybean in Ontario. Phytopathology 78:1241-1245.

8. Boland, G. J., and Hall, R. 1988. Numbers and distribution of apothecia of Sclerotinia sclerotiorum in relation to white mold of white bean (Phaseolus vulgaris). Can. J. Bot. 66:247-252.

9. Boland, G. J., and Hall, R. 1988. Relationships between the spatial pattern and number of apothecia of Sclerotinia sclerotiorum and stem rot of soybean. Plant Pathol. 37:329-336.

10. Bom, M., and Boland, G. J. 2000. Evaluation of disease forecasting variables for sclerotinia stem rot (Sclerotinia sclerotiorum) of canola. Can. J. Plant Sci. 80:889-898.

11. Butzler, T. M., Bailey, J., and Beute, M. K 1998. Integrated management of Sclerotinia blight in peanut: Utilizing canopy morphology, mechanical pruning, and fungicide timing. Plant Dis. 82:1312-1318.

12. Caesar, A. J., and Pearson, R. C. 1983. Environmental factors affecting survival of ascospores of Sclerotinia sclerotiorum. Phytopathology 73:1024-1030.

13. Coffelt, T. A., and Porter, D. M. 1982. Screening peanuts for resistance to Sclerotinia blight Plant Dis. 66:385-387. 
14. Couper, G. 2001. The biology, epidemiology and control of Sclerotinia sclerotiorum on carrots in North East Scotland. Ph.D. thesis. University of Aberdeen, Aberdeen, Scotland, UK.

15. Coyne, D. P., Steadman, J. R., and Anderson, F. N. 1974. Effect of modified plant architecture of Great Northern dry bean varieties (Phaseolus vulgaris) on white mold severity, and components of yield. Plant Dis. Rep. 58:379-382.

16. Deshpande, R. Y., Hubbard, K. G., Coyne, D. P., Steadman, J. R., and Parkhurst, A. M. 1995. Estimating leaf wetness in dry bean canopies as a prerequisite to evaluating white mold disease. Agron. J. 87:613-619.

17. Esau, K. 1940. Developmental anatomy of the fleshy storage organ of Daucus carota. Hilgardia 13:175-226.

18. Ferraz, L. C. L., Café Filho, A. C., Nasser, L. C. B., and Azevedo, J. 1999. Effects of soil moisture, organic matter and grass mulching on the carpogenic germination of sclerotia and infection of bean by Sclerotinia sclerotiorum. Plant Pathol. 48:77-82.

19. Finlayson, J. E., Rimmer, S. R., and Pritchard, M. K. 1989. Infection of carrots by Sclerotinia sclerotiorum. Can. J. Plant Pathol. 11:242-246.

20. Fuller, P. A., Coyne, D. P., Steadman, J. R., and Mumm, R. F. 1984. Inter- and intra-row intergenotypic competition influences selection for avoidance of white mold disease in dry edible beans. J. Am. Soc. Hortic. Sci. 109:567-572.

21. Fuller, P. A., Steadman, J. R., and Coyne, D. P. 1984. Enhancement of white mold avoidance in dry beans by canopy elevation. HortScience 19:78-79.

22. Geary, J. R. 1978. Host-parasite interactions between the cultivated carrot (Daucus carota L.) and Sclerotinia sclerotiorum (Lib.) de Bary. Ph.D. thesis. University of East Anglia, East Anglia, UK.

23. Geeson, J. D., Browne, K. M., and Everson, H. P. 1988. Storage diseases of carrots in EastAnglia 1978-82, and the effects of some preand post-harvest factors. Ann. Appl. Biol. 112:503-514.

24. Grau, C. R., and Radke, V. L. 1984. Effects of cultivars and cultural practices on Sclerotinia stem rot of soybean. Plant Dis. 68:56-58.

25. Hatfield, J. L. 1982. Modification of the microclimate via management. Pages 147-170 in: Biometeorology in Integrated Pest Management. J. L. Hatfield and I. J. Thomason, eds. Academic Press, New York.

26. Hunter, J. E., Pearson, R. C., Seem, R. C., Smith, C. A., and Palumbo, D. R. 1984. Relationship between soil moisture and occurrence of Sclerotinia sclerotiorum and white mold disease on snap beans. Prot. Ecol. 7:269-280.

27. Kora, C. 2003. Etiology, epidemiology, and management of Sclerotinia rot of carrot caused by Sclerotinia sclerotiorum (Lib.) de Bary. $\mathrm{Ph} . \mathrm{D}$. thesis. University of Guelph, Guelph, Ontario.

28. Kora, C., McDonald, M. R., and Boland, G. J. 2003. Sclerotinia rot of carrot: An example of phenological adaptation and bicyclic development by Sclerotinia sclerotiorum. Plant Dis. 87:456-470.

29. Le Cam, B., Rouxel, F., and Villeneuve, F. 1993. Analyse de la flore fongique de la carotte conservée au froid: Prépondérance de Mycocentrospora acerina (Hartig) Deighton. Agronomie 13:125-133.

30. Le Tourneau, D. 1979. Morphology, cytology and physiology of Sclerotinia species in culture. Phytopathology 69:887-890.

31. Lewis, B. G., and Garrod, B. 1983. Carrots. Pages 103-124 in: Post-Harvest Pathology of Fruits and Vegetables. C. Dennis, ed. Academic Press, London.

32. Lockhart, C. L., and Delbridge, R. W. 1972. Control of storage diseases of carrots by washing, grading, and postharvest fungicide treatments. Can. Plant Dis. Surv. 52:140-142.

33. Morrall, R. A. A., and Dueck, J. 1982. Epidemiology of Sclerotinia stem rot of rapeseed in Saskatchewan. Can. J. Plant Pathol. 4:161-168.

34. Mukula, J. 1957. On the decay of stored carrots in Finland. Acta Agric. Scand. Suppl. 2.

35. Park, S. J. 1993. Response of bush and upright plant type selections to white mold and seed yield of common beans grown in various row widths in southern Ontario. Can. J. Plant Sci. 73:265-272.

36. Partyka, R. E., and Mai, W. F. 1962. Effects of environment and some chemicals on Sclerotinia sclerotiorum in laboratory and potato field. Phytopathology 52:766-770.

37. Pratt, R. G. 1991. Evaluation of foliar clipping treatments for cultural control of Sclerotinia crown and stem rot in crimson clover. Plant Dis. 75:59-62.

38. Pritchard, M. K., Boese, D. E., and Rimmer, S. R. 1992. Rapid cooling and field-applied fungicides for reducing losses in stored carrots caused by cottony soft rot. Can. J. Plant Pathol. 14:177-181.

39. Saindon, G., Huang, H. C., Kozub, G. C., Mundel, H. H., and Kemp, G. A. 1993. Incidence of white mold and yield of upright bean grown in different planting patterns. J. Phytopathol. 137:118-124.

40. Salunkhe, D. K., and Desai, B. B. 1984. Vegetables: General considerations. Pages 35-52 in:
Postharvest Biotechnology of Vegetables. 1st ed. Vol. 1. CRC Press, Boca Raton, FL.

41. Schwartz, H. F., and Steadman, J. R. 1978. Factors affecting sclerotia populations of, and apothecium production by Sclerotinia sclerotiorum. Phytopathology 68:383-388.

42. Schwartz, H. F., Steadman, J. R., and Coyne, D. P. 1978. Influence of Phaseolus vulgaris blossoming characteristics and canopy structure upon resistance to Sclerotinia sclerotiorum. Phytopathology 68:465-470.

43. Snowdon, A. L. 1992. Color Atlas of PostHarvest Diseases \& Disorders of Fruits \& Vegetables. Vol. 2: Vegetables. CRC Press, Boca Raton, FL.

44. Steadman, J. R., Marcinkowska, J., and Rutledge, S. 1994. A semi-selective medium for isolation of Sclerotinia sclerotiorum. Can. J. Plant Pathol. 16:68-70.

45. Strandberg, J. O. 2001. Monitoring growth and development of carrot on organic soils in Florida. Proc. Fla. State Hortic. Soc. 114: 307-312.

46. Subbarao, K. V. 2002. Cottony rot/Pink rot Pages 29-30 in: Compendium of Umbelliferous Crop Diseases. R. M. Davis and R. N Raid, eds. American Phytopathological Society, St. Paul, MN

47. Suojala, T. 1999. Cessation of storage root growth of carrot in autumn. J. Hortic. Sci. Biotech. 74:475-483.

48. Suojala, T. 2000. Growth of and partitioning between shoot and storage root of carrot in a northern climate. Agric. Food Sci. Finland 9:49-59.

49. Teo, B. K., and Morrall, R. A. A. 1985. Influence of matric potentials on carpogenic germination of sclerotia of Sclerotinia sclerotiorum. I. Development of an inclined box technique to observe apothecium production. Can. J. Plant Pathol. 7:359-364.

50. Turkington, T. K., and Morrall, R. A. A. 1990 Influence of canopy density on risk and incidence of sclerotinia stem rot of canola. Can. J. Plant Pathol. 12:339.

51. Turkington, T. K., and Morrall, R. A. A. 1993. Use of petal infestation to forecast Sclerotinia stem rot of canola: The influence of inoculum variation over the flowering period and canopy density. Phytopathology 83:682-689.

52. Weiss, A., Hipps, L. E., Blad, B. L., and Steadman, J. R. 1980. Comparison of withincanopy microclimate and white mold disease (Sclerotinia sclerotiorum) development in dry edible beans as influenced by canopy structure and irrigation. Agric. Meteorol. 22:11-21.

53. White, J. M., and Strandberg, J. O. 1978. Early root growth of carrots in organic soil. J. Am. Soc. Hortic. Sci. 103:344-347. 